\title{
Палеогидрогеохимия нижней юры арктических районов Западной Сибири
}

\author{
Черных А.В. ${ }^{1}$, Новиков Д.А. ${ }^{1,2}$, Дульцев Ф.Ф. ${ }^{1}$, Борисов Е.В. ${ }^{1}$ \\ ${ }^{1}$ Институт нефтегазовой геологии и геофизики им. А.А. Трофимука СО РАН, Новосибирск, \\ ChernykhAV@ipgg.sbras.ru \\ ${ }^{2}$ Новосибирский национальный исследовательский государственный университет, Новосибирск
}

Аннотация. Палеогидрогеологическая история арктических районов Западной Сибири включает в себя 4 гидрогеологических цикла: индско-синемюрский, плинсбахско-сеноманский, туронско-серраваллийский, тортонско-голоценовый. В работе рассмотрена палеогидрогеохимия концаиндско-синемюрского и начала плинсбахо-сеноманского цикла. В целом, в геттанге и синемюрене всей территории доминировали континентальный режим осадконакопления, денудационные процессы и процессы инфильтрации пресных атмосферных водгидрокарбонатного кальциевого состава. В плинсбахе началась трансгрессия моря, минерализация сингенетичных вод в наиболее погруженных частях бассейна достигала до 20-25 г/дм³. Во время крупнейшей трансгрессии в тоарском веке, глубины моря достигали 100 метровв центральных частях бассейна, а минерализация сингенетичных хлоридных натриевых вод могла достигать 30 г/дм².

Ключевые слова:гидрогеологический цикл, палеогидрогеохимия, инфильтрация, элизия, Западная Сибирь, Арктика.

\section{Paleohydrogeochemistry of the Lower Jurassic deposits in the Arctic regions of West Siberia}

\author{
Chernykh A.V. ${ }^{1}$, Novikov D.A. ${ }^{1,2}$, Dultsev F.F. ${ }^{1}$, Borisov E.V. ${ }^{1}$ \\ ${ }^{1}$ Trofimuk Institute of Petroleum Geology and Geophysics of SB of RAS. ChernykhAV@ipgg.sbras.ru \\ ${ }^{2}$ Novosibirsk State University
}

\begin{abstract}
The paleohydrogeological history of the Arctic regions of West Siberia includes 4 hydrogeological cycles: the Induan-Sinemurian, Pliensbachian-Cenomanian, Turonian-Serravallian, and Tortonian-Holocene. Paper considers paleohydrogeochemistry of the end of the Induan-Sinemurian and the beginning of the PliensbachianCenomanian cycle. During the hettangian and the sinemurainages the continental sedimentation regime, denudation processes, and the processes of infiltration of fresh atmospheric water (with a carbonate calcium composition) dominated throughout the territory. The transgression starts in the Pliensbachian, the salinity of syngenetic waters in the deepest parts of the basin reached 20-25 g/l. During the largest transgression in the Toarian age, the depths of the sea reached $100 \mathrm{~m}$ in the central parts of the sea basin, and the salinity of syngenetic chloride sodium waters could reach $30 \mathrm{~g} / \mathrm{dm}^{3}$.

Key words: Hydrogeological cycle, paleohydrogeochemistry, infiltration, elision, West Siberia, Arctic region.
\end{abstract}

Современные палеогидрогеологические исследования требуют комплексного рассмотрения данных по большинству геологических областей: гидрогеологии, литологии, стратиграфии, тектонике и т.д. Результаты этих исследований помогают в решении многих вопросов современной гидрогеохимии нефтегазоносных отложений, включая формирование состава подземных вод, их генезис, типы вертикальной гидрогеохимической зональности, процессы нефтегазообразования и нефтегазонакопления и другие (Li et al., 2001; Шварцев и др., 2004; Rosenthal et al., 2006; Drake et al., 2009; Hendry et al., 2013; Khan et al., 2011; Novikov, 2017; Novikov et al., 2018; Yousif et al., 2018; Novikov et al., 2019; Новиков, 2019; Новиков и др., 2019 а; Новиков и др., 2019 б).

В основу работы по проведению палеогидрогеохимических реконструкций была заложена методика восстановления солевого состава вод древних бассейнов (Басков, 1983; Садыкова и др., 2017; Садыкова и др., 2018; Sadykova, 2018).В условиях континентального осадконакопления в денудационных и денудационно-аккумулятивных областях (низкие горы, денудационные плато) доминируют процессы инфильтрации гидрокарбонатных кальциевых вод с величиной общей минерализации до 0.5 г/дм³ . В обстановках возвышенных равнин формируются пресные и солоноватые воды. Они характеризуются гидрокарбонатным кальциевым составом с величиной общей ми- 
нерализации, изменяющейся в пределах от 0.5 до 1.5 г/дм³, содержания хлорид-иона и натрия до 25 \%-экв.Воды гидрокарбонатного кальциевого составас содержанием хлорид-иона и натрия до 25 \%-экв.с величиной общей минерализации 1.5-2.0 г/дм³ установлены в пределах денудационноаккумулятивных равнин. В условиях низменных аккумулятивных равнин захораниваются солонова-


иона и кальция до 25 \%-экв. При обстановках переходного осадконакопления (прибрежное мелководье и прибрежно-морская равнина) формируются воды хлоридного натриевого состава с содержанием катионов кальция и магния до 25 \%-экв. и с величиной общей минерализации 5-15 г/дм³. В мелководно-морских условиях, где глубины моря не превышают 25 м, установлены соленые морские воды хлоридного натриевого состава с содержанием катионов магния до 25 \%-экв. и минерализацией 15.0-20.0 г/дм³ . В обстановках, где глубины моря варьируют от 25 до 200 м, величина общей минерализации хлоридных натриевых вод с содержанием катионов магния до 25 \%-экв. вод достигает 20.0-35.0 г/дм³ . В глубоководных обстановках минерализация соленых хлоридных натриевых вод с содержанием катионов магния до 25 \%-экв. вод могла достигать 40.0 г/дм³. Также, в основу исследования легли палеогеографические карты юрского периода (Конторович и др., 2013). База данных по арктическим районам Западной Сибири включает в себя результаты испытания более 4000 объектов 251 поисковой площади и данные полного химического анализа 7213 проб подземных вод.

По результатам проведенных реконструкций в истории арктических районов Западной Сибири можно выделить индско-синемюрский, плинсбахско-сеноманский, туронско-серраваллийский, тортонско-голоценовыйгидрогеологические циклы. В данном исследовании рассматривается конец индско-синемюрского и начало плинсбахо-сеноманского цикла, т.к. объектом исследования были выбраны нижнеюрские отложения.

В геттанге и синемюре аллювиальные и аккумулятивные равнины являлись преобладающими обстановками осадконакопления, а Таймырские горы и Новая Земля послужили источниками сноса в северной части исследуемого региона. Доминировали денудационные процессы и процессы инфильтрации атмосферных осадков. Захоранивались воды преимущественно гидрокарбонатного кальциевого состава с соленостью, не превышающей 0.5-1.5 г/дм³.

Начавшаяся в плинсбахе трансгрессия привела к образованию в пределах Ямальского и Гыданского полуостровов мелководного морского бассейна, в пределах которого минерализация вод варьировала в пределах 2-15 г/дм³ (рис. 1). На эти колебания указывают немногочисленные находки брахиоподов и аммонитов и высокие концентрации пелеципод, а также поглощенный комплекс глин (Грамберг, 1973; Шурыгин и др., 2000). Сингенетичные воды имели хлоридный натриевый состав с содержанием гидрокарбонат-иона и кальция до $25 \%$-экв. и минерализацией от 2 до 5 г/дм³. В южной части региона исследования установлен переход прибрежно-морских обстановок в континентальные, где доминировали процессы инфильтрации атмосферных осадков. Внешними областями питания и источниками сноса в этот период являлись Новоземельская, Средне-Сибирская, Таймырская и Уральская возвышенности, в их пределах формировались гидрокарбонатные кальциевые воды с минерализацией до 0.5 г/дм ${ }^{3}$

В результате происходившей в тоарское время крупнейшей трансгрессии в регионе исследования значительно увеличились область морского осадконакопления и глубины морского бассейна (до 100 м в Антипаютинско-Тадебияхинской, Большехетской, Карской мегасинеклизах и АгапскоЕнисейском желобе) (рис. 2). Установление нормально-морского режима седиментации подтверждают находки двустворок, ростров белемнитов и фораминифер (Конторович и др., 2013). Отложения Илыкитербютской свиты, одной из нефтематеринских толщ в регионе, накапливались в глубоководных частях бассейна, где величина минерализации сингенетичных хлоридных натриевых вод достигала 35-38 г/дм³ . Восточные и западные границы морского бассейна в тоарское время имели схожие очертания с плинсбахом.

Площадь морского осадконакопления сократилась на северо-западе территории исследования в тоарско-раннеааленское время из-за расширения зоны мелководья, с глубинами бассейна до 25 м. В наиболее глубоких участках продолжалось накопление глин, а в бортовых частях установ- 


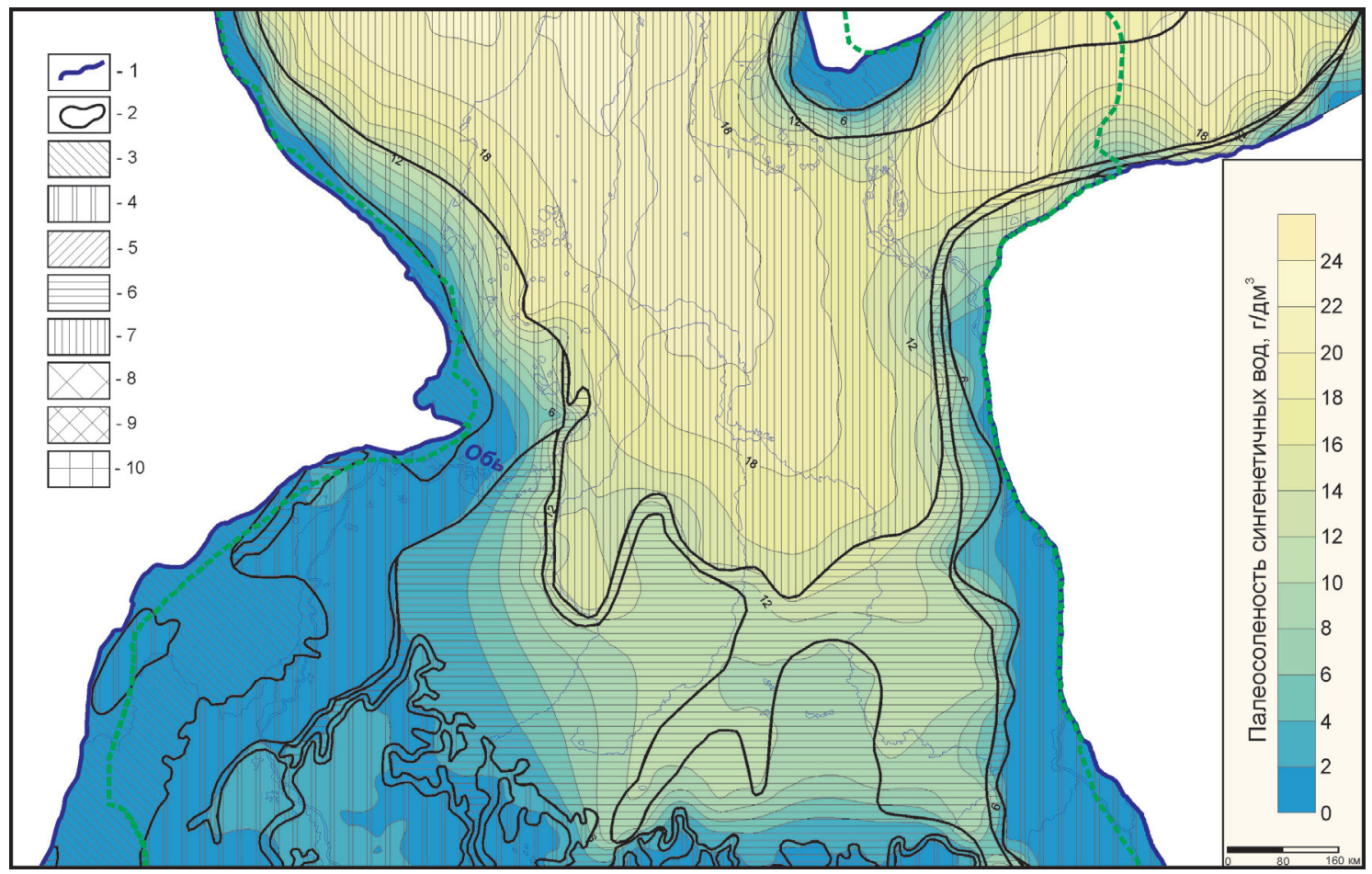

Рис. 1. Палеогидрогеохимическая карта на плинсбахский век.

1 - граница юрского осадочного бассейна; 2 - граница палеогидрогеохимических зон: 3 - низкие горы, водыгидрокарбонатного кальциевого состава $(\mathrm{M}$ до 0.5 г/дм³ $) ; 4$ - возвышенная равнина, воды гидрокарбонатного кальциевого состава(Мот 0.5 до 1.5 г/дм³), содержание ионов хлора и катионов натрия до $25 \%$-экв.; 5 - денудационно-аккумулятивная равнина, воды гидрокарбонатного кальциевого состава (Мот 1.5 до 2.0 г/дм³), содержание ионов хлора и катионов натрия до 25 \%-экв.; 6 - низменная аккумулятивная равнина, воды хлоридного натриевого состава (Мот 2.0до 5.0 г/дм3),содержание гидрокарбонат-иона и катионов кальция до 25 \%-экв.; 7 - прибрежная равнина, водыхлоридного натриевого состава(Мот 5,0до 15,0 г/дм³),содержание катионов кальция и магния до 25 \%-экв.; 8 - прибрежная зона до 25 м глубиной, водыхлоридного натриевого состава(Мот 15.0до 20.0 г/дм³),содержание катионов магния до 25 \%-экв.; 9 - море с глубинамиот 25 до 200 м, воды хлоридного натриевого состава(М от 20.0 до 35.0 г/дм³), содержание катионов магния до 25 \%-экв.; 10 - море с глубинамиот 200 до 400 м, водыхлоридного натриевого состава (Мдо 40.0 г/дм³),содержание катионов магния до 25 \%-экв.

Fig. 1. Paleohydrogeochemical map for the Pliensbachian age.

1 - boundary of the Jurassic sedimentary basin; 2 - boundary of paleohydrogeochemical zones: 3 - low mountains, water of a hydrocarbonate calcium composition (M up to $0.5 \mathrm{~g} / \mathrm{dm}^{3}$ ); 4 - elevated plain, water of a hydrocarbonate calcium composition ( $\mathrm{M}$ from 0.5 to $1.5 \mathrm{~g} / \mathrm{dm}^{3}$ ), the content of chlorine ions and sodium cations up to $25 \%$-eq.; 5 -denudation-accumulative plain, calcium hydrogen carbonate water ( $\mathrm{M}$ from 1.5 to $2.0 \mathrm{~g} / \mathrm{dm}^{3}$ ), the content of chlorine ions and sodium cations up to $25 \%$-eq.; 6 - low-lying accumulative plain, water of sodium chloride composition (M from 2.0 to $5.0 \mathrm{~g} / \mathrm{dm}^{3}$ ), the content of bicarbonate ion and calcium cations up to $25 \%$-eq.; 7 - coastal plain, water of sodium chloride composition ( $\mathrm{M}$ from 5.0 to $15.0 \mathrm{~g} / \mathrm{dm}^{3}$ ), the content of calcium and magnesium cations up to $25 \%$-eq.; 8 - coastal zonewith depths up to $25 \mathrm{~m}$, water of sodium chloride composition (M from 15.0 to $20.0 \mathrm{~g} /$ $\mathrm{dm}^{3}$ ), the content of magnesium cations is up to $25 \%$-eq.; 9 - sea with depths from 25 to 200 m, water of sodium chloride composition ( $\mathrm{M}$ from 20.0 to $35.0 \mathrm{~g} / \mathrm{dm}^{3}$ ), the content of magnesium cations is up to $25 \%$-eq.; 10 - seawith depthsfrom 200 to $400 \mathrm{~m}$, water of sodium chloride composition ( $\mathrm{M}$ up to $40.0 \mathrm{~g} / \mathrm{dm}^{3}$ ), the content of magnesium cations up to $25 \%$-eq.

лено увеличение грубообломочных фракций и появление песчанистых пластов. Границы денудационных и прибрежных равнин в это время сохраняли свои очертания.

По результатам комплексного анализа современной геохимии подземных вод нефтегазоносных отложений и детальных палеогидрогеохимических реконструкций можно сделать вывод, что 




Рис. 2. Палеогидрогеохимическая карта на тоарский век. Усл. обозначения см. рис. 1.

Fig. 2. Paleohydrogeochemical map for the Toarcian age. For legend, see Fig. 1.

в резервуарах нижней юры большим распространением пользуются седиментогенные подземные воды, которые могут быть смешаны с древними инфильтрогенными, проникшими в результате регрессии морского бассейна.

Исследования проводились при финансовой поддержке проекта ФНИ № 0331-2019-0025 «Геохимия, генезис и механизмы формирования состава подземных вод арктических районов осадочных бассейнов Сибири», РФФИ в рамках научного проекта № 18-05-70074 «Ресурсы Арктики», РФФИ и Правительства Ямало-Ненецкого автономного округа в рамках научного проекта № 19-45-890005.

\section{Литература}

1. Басков Е.А. Основы палеогидрогеологии рудных месторождений. Л. Изд-во: Недра. 1983. 263 с.

2. Новиков Д.А. Роль элизионного водообмена в формировании гидродинамического поля ЯмалоКарской депрессии // Литология и полезные ископаемые. 2019. № 3. C. 248-261. DOI: 10.31857/S0024497Х20193248-261.

3. Новиков Д.А., Вакуленко Л.Г., Ян П.А. Особенности латеральной гидрогеохимической и аутигенноминералогической зональности оксфордского регионального резервуара Надым-Тазовского междуречья // Геология и геофизика. 2019. Т. 60. № 6. С. 843-859. DOI: 10.15372/GiG2019041.

4. Новиков Д.А., Черных А.В., Садыкова Я.В., Дульцев Ф.Ф., Хилько В.А., Юрчик И.И. Эволюция гидрогеохимического поля северных и арктических районов Западно-Сибирского осадочного бассейна в мезозое // Известия Томского политехнического университета. Инжиниринг георесурсов. 2019. Т. 330. № 10. С. 165-180. DOI: 10.18799/24131830/2019/10/2314.

5. Садыкова Я.В., Дульцева М.Г. Роль палеогидрогеохимических факторов в формировании состава подземных вод нефтегазоносных отложений северо-восточной части Большехетской мегасинеклизы // Водные ресурсы. 2017. Т. 44. № 2. C. 168-181. DOI: 10.1134/S0097807817020130.

6. Садыкова Я.В., Новиков Д.А., Черных А.В., Дульцев Ф.Ф. Палеогидрогеохимия верхнеюрских отложений арктических районов Западной Сибири // Материалы Всероссийского совещания по подземным водам Востока России. 2018. С. 412-417.

7. Конторович А.Э., Конторович В.А., Рыжкова С.В., Шурыгин Б.Н., Вакуленко Л.Г., Гайдебурова Е.А., Данилова В.П., Казаненков В.А., Ким Н.С., Костырева Е.А., Москвин В.И., Ян П.А. Палеогеография ЗападноСибирского осадочного бассейна в юрском периоде // Геология и геофизика. 2013. Т. 54. № 8. Р. 972-1012. 
8. Грамберг И.С. Палеогидрогеохимия терригенных толщ. Л. Изд-во: Недра. 1973. 172 с.

9. Шварцев С.Л., Новиков Д.А. Природа вертикальной гидрогеохимической зональности нефтегазоносных отложений (на примере Надым-Тазовского междуречья, Западная Сибирь) // Геология и геофизика. 2004. Т. 45. № 8. С. 1008-1020.

10. Шурыгин Б.Н., Никитенко Б.Л., Девятов В.П., Ильина В.И., Меледина С.В., Гайдебурова Е.А., Дзюба О.С., Казаков А.М., Могучева Н.К. Стратиграфия нефтегазоносных бассейнов Сибири. Юрскаясистема. Новосибирск. Изд-во: СОРАН филиал «ГЕО». 2000. 480с.

11. Drake H., Tullborg E.L. Paleohydrogeological events recorded by stable isotopes, fluid inclusions and trace elements in fracture minerals in crystalline rock, Simpevarp area, SE Sweden // Applied Geochemistry. 2009. № 24. P. 715-732. DOI:10.1016/j.apgeochem.2008.12.026.

12. Hendry M.J., Barbour S.L., Novakowski, Wassenaar L.I. Paleohydrogeology of the Cretaceous sediments of the Williston Basin using stable isotopes of water // Water Resources Research. 2013. V. 49. P. 4580-4592. DOI: $10.1002 /$ wrer.20321.

13. Khan Z.A., Tewari R.C. Paleochannel and paleohydrology of a Middle Siwalik (Pliocene) fluvial system, northern India // Journal of Earth System Science. 2011. V. 120. Iss. 3. P. 531-543. DOI: 10.1007/s12040-011-0083-4.

14. Li Y., Wang Y., Deng A. Paleoclimate record and paleohydrogeological analysis of travertine from the Niangziguan Karst Springs, northern China // Science in China. 2001. V. 44. P. 114-118.

15. Novikov D.A. Hydrogeochemistry of the Arctic areas of Siberian petroleum basins // Petroleum Exploration and Development. 2017. V. 44. № 5. P. 780-788. DOI: 10.1016/S1876-3804(17)30088-5.

16. Novikov D.A., Sadykova Y.V., Chernykh A.V., Dultsev F.F., Sukhorukova A.F. Paleohydrochemistry of Jurasic and Cretaceous deposits in arctic regions of Western Siberia // IOP Conference Series: Earth and Environmental Science. 2018. V. 193. № 012051. DOI: 10.1088/1755-1315/193/1/012051.

17. Novikov D.A., Chernykh A.V., Dultsev F.F. Paleohydrogeochemistry of the Upper Jurassic Deposits of the Arctic Regions of the West Siberian Megabasin // Journal of Physics: Conference Series. 2019. V. 1172 (1). № 012094. DOI: 10.1088/1742-6596/1172/1/012094.

18. Rosenthal E., Flexer A., Möller P. The paleoenvironment and the evolution of brines in the Jordan-Dead Sea transform and in adjoining areas // International Journal of Earth Sciences. 2006. № 95. P. 725-740. DOI: $10.1007 / \mathrm{s} 00531-005-0057-3$

19. Sadykova Y.V. Singenetic waters composition reconstruction methods of mesozoic sedimentary basins // IOP Conf. Ser.: Earth and Environmental Science. 2018. V. 193 (1). № 012059. DOI: 10.1088/1755-1315/193/1/012059.

20. Yousif M., Henselowsky F., Bubenzer O. Palaeohydrology and its impact on groundwater in arid environments: Gebel Duwi and its vicinities, Eastern Desert, Egypt // Catena. 2018. V. 171. P. 29-43. DOI: 10.1016/j.catena.2018.06.028. 